\title{
Inexpensive Method to Assess Mangroves Forest through the Use of Open Source Software and Data Available Freely in Public Domain
}

\author{
Fatwa Ramdani 1*, Sabaruddin Rahman², Putri Setiani ${ }^{3}$ \\ ${ }^{1}$ Geoinformatic Research Center, Information Technology and Computer Science, Brawijaya University, Malang, \\ Indonesia \\ ${ }^{2}$ Department of Ocean Engineering, Faculty of Engineering, Hasanuddin University, \\ Makassar, Indonesia \\ ${ }^{3}$ Graduate School of Environmental Studies, Tohoku University, Sendai, Japan \\ Email: ${ }^{*}$ fatwaramdani@ub.ac.id
}

Received 5 January 2015; accepted 28 January 2015; published 2 February 2015

Copyright (C) 2015 by authors and Scientific Research Publishing Inc.

This work is licensed under the Creative Commons Attribution International License (CC BY). http://creativecommons.org/licenses/by/4.0/

(c) (i) Open Access

\begin{abstract}
Mapping and assessment of mangrove environment are crucial since the mangrove has an important role in the process of human-environment interaction. In Indonesia alone, $25 \%$ of South East Asia's mangroves available are under threat. Recognizing the availability and the ability of new sensor of Landsat data, this study investigates the use of Landsat ETM + 7 and Landsat 8, acquired in 2002 and 2013 respectively, for assessing the extent of mangroves along the South Sulawesi's coastline. For each year, a supervised classification of the mangrove was performed using open source GRASS GIS software. The resulting maps were then compared to quantify the change. Field work activities were conducted and confirmed with the changes that occurred in the study area. Considering the accuracy assessment, our study shows that the RGB composite color-supervised classification is better than band ratio-supervised classification methods. By linking the open source software with the Landsat data and Google Earth satellite imagery that is available in public domain, mangroves forest conversion and changes can be observed remotely. Ground truth surveys confirmed that, decreases of mangroves forest is due to the expansion of fishpond activity. This technique could potentially allow rapid, inexpensive remote monitoring of cascading, indirect effects of human activities to mangroves forest.
\end{abstract}

\footnotetext{
${ }^{*}$ Corresponding author.
}

How to cite this paper: Ramdani, F., Rahman, S. and Setiani, P. (2015) Inexpensive Method to Assess Mangroves Forest through the Use of Open Source Software and Data Available Freely in Public Domain. Journal of Geographic Information System, 7, 43-57. http://dx.doi.org/10.4236/igis.2015.71004 


\section{Keywords}

\section{Mangroves, Coastal Zone, Classification, Remote Sensing, Landsat TM/ETM+, Indonesia}

\section{Introduction}

Mangrove forests are among the most productive and biologically important ecosystems of the world because they provide important and unique ecosystem goods and services to human society, coastal and marine systems. The forests help stabilize shorelines and reduce the devastating impact of natural disasters such as tsunamis [1] and storms [2].

The mangrove biome dominates tropical and sub-tropical coastlines between latitudes $32^{\circ} \mathrm{N}$ and $38^{\circ} \mathrm{S}$ and covers approximately 22 million hectares. Around $28 \%$ of global mangroves are located in Southeast Asia, with Indonesia alone accounting for $25 \%$ [3]. Indonesia has by far the largest stock of mangroves in 2000 but also faces the largest losses over the period 2000-2050 both in absolute and proportionate terms, approximately 1.7 million hectares and $38 \%$ respectively [4].

Compared to other countries in Southeast Asia, Indonesia has the highest diversity with 43 true mangrove species [5]. In 2003, mangrove forests covered an area of 3,062,300 ha along the coastal area of Indonesia and thus represented the largest extent of mangroves worldwide [5].

The status of the mangrove environment in Indonesia has been assessed in some studies ([6] [7]). Furthermore, the socio-economic-ecology linkages of mangrove utilization in Indonesia have also been documented ([8][13]).

Unfortunately, it has been reported that worldwide, including in Indonesia, the area of mangrove forests have declined at a faster rate than inland tropical forests and coral reefs [14]. Among the major causes, the continued decline in the mangrove forests is mainly induced by anthropogenic activity, including mangrove conversion to agriculture, aquaculture, tourism, urban development and over exploitation of resources and unsustainable land use practices in the surrounding mangrove area ([15]-[17]). Due to intensive conversion for cultivation activities alone, mangrove area in Indonesia has been declining from 5.2 million hectares in 1982, to 3.2 million hectares in 1987 and further to 2.4 million hectares in 1993 [18]. One of the most intense cases of mangrove area declination in Indonesia is in the mangrove forest located within the Segara Anakan Lagoon, Java Island. Since 1978, anthropogenic activities including urbanization, agriculture (mainly rice fields) and aquaculture activities has led to the loss of about $51.5 \%$ of the mangrove area [19].

Other major threats to mangrove forest in Indonesia are oil spill from oil refinery industries and the relative sea-level rise [20].

For the protection of the mangrove forest the Indonesian government passed the regulation that a 50 - $200 \mathrm{~m}$ wide belt of mangroves has to be retained along the coast to preserve the ecological functions and ensure the natural regeneration process [21]. However, the illegal mangrove forest conversion is still happening in Indonesia recently.

To preserve and protect the mangrove forest area from further illegal conversion, intensive mapping and monitoring is required. Yet considering the vast area, direct monitoring will require high cost and long period of time. Remote sensing provides lots of options for continuous monitoring of mangrove over different periods. On this note, mapping and monitoring techniques for the mangrove environment has been widely studied.

A work by Souza-Filho et al. [22] used remotely-sensed data for mangrove mapping as a geological indicator of coastal changes in the Brazilian Amazon. The investigation was based on orbital of SAR data. The orbital SAR corresponded to C-HH band imagery relating to the 1998 RADARSAT-1 Fine Mode with a 10-meter nominal ground resolution. Orbital optical data correspond to Landsat 5 TM and SPOT 4 HRV images with a nominal resolution around $30 \mathrm{~m}$. The methodology employed in this study has been costly since theRADARSAT-1 data is expensive and not available in the public domain.

Another study by Li [23] monitored the changed of mangrove forests in southern China using multi-temporal Lands at imagery. Land use and land cover data sets were generated for the reserve for multiple years via unsupervised classification using Landsat time series images. The unsupervised Iterative Self-Organizing Data Analysis Technique Algorithm (ISODATA) was implemented to create 30 spectral clusters. Post-classifications 
or further improvements on the classifications were also made by eliminating apparent gross errors through hand editing. This method is time-cost and insufficient for large scale and regional analysis, because the errors need to be revised through hand editing.

Nascimento et al. [24] analyzed the ability of Synthetic Aperture Radar (SAR) for providing cloud-free observations, hence this study investigated the use of JERS-1 SAR and ALOS PALSAR data, an object-oriented classification of major land covers was performed with the resulting maps than compared to quantify change. However, application of this method is relatively costly since the ALOS PALSAR data are commercial remote-sensed data, particularly for mangrove monitoring in developing countries with large mangrove forest areas such as Indonesia, which require an extensive amount of data.

A monitoring and mapping method for mangrove area which is cost-effective, e.g. applying free software and public data, will then be of great advantage. The present study aimed to develop an accurate and inexpensive classification method that will enable a more sustainable management of mangrove conservation.

Accessibility of Landsat data is freely available, and the recent launch of Landsat 8 will ensure the continued acquisition and availability of Landsat data utilizing a two-sensor payload, the Operational Land Imager (OLI) and the Thermal InfraRed Sensor (TIRS). Respectively, these two instruments will collect image data for nine shortwave bands and two longwave thermal bands.

Providing moderate-resolution imagery, from 15 meters to 100 meters, of Earth's land surface and polar regions, Landsat 8 operates in the visible, near-infrared, short wave infrared, and thermal infrared spectrum. It also captures approximately 400 scenes a day, an increase from the 250 scenes a day on Landsat 7 [25].

OLI sensor collects data from nine spectral bands. Seven of the nine bands were consistent with the Thematic Mapper (TM) and Enhanced Thematic Mapper Plus (ETM+) sensors found on earlier Landsat satellites, which provides compatibility with the historical Landsat data, while also improving measurement capabilities. Two new spectral bands, a deep blue coastal/aerosol band and a shortwave-infrared cirrus band will be collected, allowing scientists to measure water quality and improve detection of high, thin clouds [25].

This study utilizes the benefit of new Landsat 8 data to develop a method of mangrove mapping and assessment. A supervised classification technique was developed for mapping and assessing the mangrove environment along South Sulawesi coastline, with specific focus along coastal environment in Maros Regency, the South Sulawesi Province, Indonesia. The study area was chosen, because the coastal environment in Maros Regency is one of the places that are under threat from anthropogenic activity.

The method was performed using free open source GRASS GIS and Quantum GIS software (available at http://www.qgis.org/en/site/forusers/download.html). Both are distributed as free software under the GNU Public License. GRASS GIS and Quantum GIS software presently are integrated in one graphical user interface, enabling the seamless combination of both software.

\section{Data}

Multispectral images of Landsat 8 OLI (for year 2013) and Landsat 7 ETM+(for year 2002) acquired from http://earthexplorer.usgs.gov/, both at the spatial resolution of $15 \mathrm{~m}$ after fusion technique employed, using panchromatic band, were used in this study. The multispectral imagery consists of 11 spectral bands and 8 spectral bands respectively, for Landsat 8 OLI and Landsat 7 ETM+. The imageries were acquired over the Makassar Strait region (Figure 1).

\section{Methodology}

\subsection{Pre-Processing}

Pre-processing, such as radiometric and atmospheric corrections, which is necessary for analysis of vegetation indices and land use/land cover parameters, were conducted. The Landsat 8 and 7 ETM+ level 1G images were geometry-corrected products.

The Landsat 8 and 7 ETM+ imagery were converted from digital numbers (DN) to Top-of-atmospheric (TOA) reflectance using a two-step process. The initial step is converting the DN values into radiance values using the Lmin and Lmax spectral radiance scaling factors. The values are specific to the individual scene and are produced in the image header file. However, the new .MTL file of Landsat 7 ETM+ data has "mult" and "add" values that are similar to Landsat 8. These values can be read as gain and bias for TOA radiance calibration. "Mult" is a multiplicative rescaling factor, while "add" is an additive rescaling factor for each band. 


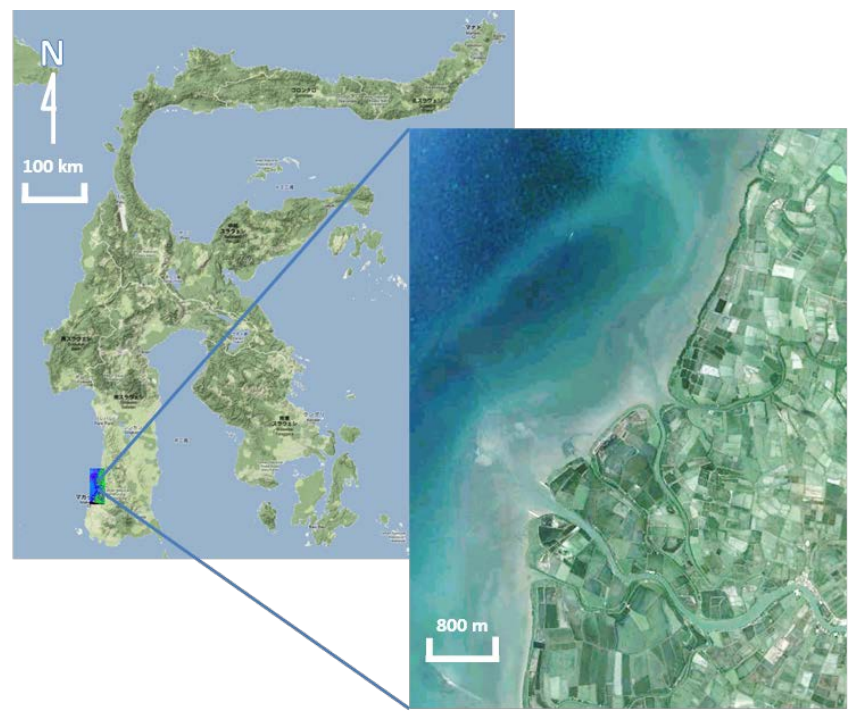

Figure 1. Study area located in Maros Regency, South Sulawesi Province, Indonesia. Images are from Google Earth.

The second step is converting the radiance data into reflectance using the equations from the Landsat 7 Science Data Users Handbook to the ETM+ image [26] and equations from USGS were applied to the Landsat 8 image [27]. During this step, each scene of pixel values from bands 1 - 5 and band 7 was atmospherically corrected as reflectance.

The calculation method for image processing in GRASS GIS employs mathematical operators and functions in expressions involving maps or images. The maps and images which are stored in raster grid-cell format are two-dimensional matrices of integer values. The syntax for the algebra is result $=$ expression where expression is built using maps and images, mathematical operators, functions, and temporary variables [28]. The resulting map is produced by evaluating the expression for each cell in the matrix. For example, the expression of:

$$
\text { Result }=\text { map } 1 \times \text { map2 }
$$

would produce a map Result where each cell is the multiplication of the values of the corresponding cells in map 1 and map 2.

To convert the DN values into reflectance in GRASS GIS software, we employed the "r.mapcalc" expression in the command console. In the command console of GRASS GIS, the formula to convert the DN of the Landsat 8 is written as follows (Equation (1)):

$$
\begin{gathered}
\text { r.mapcalc } \\
\mathrm{B}(\mathrm{i}) \mathrm{TOA}=\text { REFLECTANCE_MULT_BAND }(\mathrm{i}) \times \mathrm{B}(\mathrm{i})+\text { REFLECTANCE_ADD_BAND }(\mathrm{i})
\end{gathered}
$$

where,

B(i)TOA = Name for output of TOA planetary reflectance of Band (i).

REFLECTANCE_MULT_BAND(i) = Band (i) multiplicative rescaling factor from the metadata (.MTL).

$\mathrm{B}(\mathrm{i})=$ Quantized and calibrated standard product pixel values $(\mathrm{DN})$ of Band (i).

REFLECTANCE_ADD_BAND(i) = Band (i) additive rescaling factor from the metadata.

\subsection{Derivations of NDVI and NDWI}

The NDVI (Normal Difference Vegetation Index) [29] and NDWI (Normal Difference Water Index) [30] was then performed for each image. This was employed to separate mangrove vegetation along the coastline from water and soil.

NDVI has been widely monitored the quality and distribution of vegetation. This index can be computed using a simple formula (Equation (2)),

$$
\text { NDVI }=(\text { NIR }- \text { Red }) /(\text { NIR }+ \text { Red }) \text {. }
$$


where Red is the reflectance or radiance in a visible wavelength channel $(0.630-0.690 \mu \mathrm{m})$, and corresponds to band 3 and band $4(0.630-0.680 \mu \mathrm{m})$ for ETM+ and OLI images, respectively. In the command console of GRASS GIS, the formula to calculate NDVI is written as follows (Equation (3)):

$$
\text { r.mapcalc ndvi }=1.0 \times(\mathrm{B} 4-\mathrm{B} 3) /(\mathrm{B} 3+\mathrm{B} 4) \text {. }
$$

NDWI is sensitive to changes in the water content of vegetation canopies. It is considered as an independent vegetation index that was developed to delineate vegetation water content features, and to enhance their presence in remotely-sensed digital imagery. NDWI is expressed using the following (Equation (4)):

$$
\text { NDWI }=(\text { NIR }- \text { SWIR }) /(\text { NIR }+ \text { SWIR }) \text {. }
$$

where,

NIR is the reflectance or radiance in a near infra-red wavelength channel $(0.760-0.900 \mu \mathrm{m})$, and SWIR is the reflectance or radiance in a short wave infrared wave-length channel $(1.550-1.750 \mu \mathrm{m})$.

NIR and SWIR correspond to bands 4 and 5 for ETM+ images, respectively. While for OLI images, NIR and SWIR correspond to band 5 (NIR, $0.845-0.885 \mu \mathrm{m}$ ) and band 6 (SWIR, $1.560-1.660 \mu \mathrm{m}$ ). In the command console of GRASS GIS, the formula to calculate NDWI of the Landsat 8 OLI is written as follows (Equation (5)):

$$
\text { r.mapcalc ndwi }=1.0 \times(\mathrm{B} 5-\mathrm{B} 6) /(\mathrm{B} 5+\mathrm{B} 6) \text {. }
$$

\subsection{RGB Composite Color}

An RGB (Red-Green-Blue) colour composite was produced using a blue band of Landsat 7 ETM+ and a deep blue coastal band of Landsat 8 OLI respectively in the Red channel, NDVI, and NDWI images were loaded into the green and blue channels, respectively. To produce RGB colour composite images, we used the "r.composite" expression in GRASS GIS software (Equation (6)).

$$
\text { r.composite } \mathrm{r}=\text { Blue } \mathrm{g}=\text { NDVI } \mathrm{b}=\text { NDWI output }=\text { Mangrove8 }
$$

where,

$r=$ Red channel.

$\mathrm{g}=$ Green channel.

$\mathrm{b}=$ Blue channel.

output $=$ The resulting raster map name of colour composite.

\subsection{Image Fusion}

A data fusion technique was performed using the RGB image and the panchromatic band of Landsat 8 and 7 $\mathrm{ETM}+$. Image fusion was performed to prepare data for visual interpretation and enhance the classification result. The high spatial resolution of the panchromatic image (Band 8) with the multispectral content of multiband images was fused into a single band. Since the Landsat 8 OLI store values as "DN" from zero to 65,535, we need to rescale it into zero to 255 to get an acceptable color-balanced composite image after pan-sharpening. Rescale method can be done using the "r.rescale" expression on the command console of GRASS GIS (Equation (7)). This study employed the Brovey spectral sharpening technique [31] which can be employed using the "i.fusion.brovey" expression in GRASS GIS software (Equation (8)).

$$
\begin{aligned}
& \text { r.rescale in }=\mathrm{B}(\mathrm{i})_{-} \text {DNs out }=\mathrm{B}(\mathrm{i})_{-} \text {DNs_ } 255 \text { from }=0,65535 \text { to }=0,255 \\
& \text { i.fusion.brovey } \mathrm{ms} 1=\mathrm{B} 2 \mathrm{~ms} 2=\mathrm{B} 4 \mathrm{~ms} 3=\mathrm{B} 5 \mathrm{pan}=\mathrm{B} 8 \text { outputprefix }=\text { fused7 }
\end{aligned}
$$

where,

ms1 = Name of input raster map (Green: B2).

ms2 = Name of input raster map (NIR: B4).

ms3 = Name of input raster map (MIR: B5).

Pan $=$ Name of input raster map (Pancromatic: B8).

output prefix = Name for output raster map prefix (e.g. "fused7”).

in $=$ The name of the raster map to be rescaled. 
out $=$ The resulting raster map name.

from $=$ min, $\max$ (the input data range to be rescaled).

to $=\min , \max$ (the output data range).

\subsection{Image Classification}

Image classification was performed on the fused image result. A maximum likelihood decision rule method was used to extract a mangrove map. Two classes were defined for the mangrove map: mangrove forest and nonmangrove forest (water, fishpond, built-up area). After the classification, the raster classification result was then converted into vector format.

Prior to classification, satellite images were subsetted to include only areas where mangrove forest is likely to occur. Based on the field work survey, mangroves 10 meters above sea level (masl) and $2 \mathrm{~km}$ of coastline were observed. The image was a subset by elevation using a digital elevation model (DEM) extracted from ASTER GDEM data to confine the mapping area below 10 masl. We performed a neighborhood filter on the ASTER GDEM data using the "r.neighbors" expression (Equation (9)), and extracted contour line using the "r.contour" expression (Equation (10)) in GRASS GIS software.

$$
\begin{gathered}
\text { r.neighbors input }=\text { Maros_Aster output }=\text { Maros_filter } \\
\text { r.contour input }=\text { Maros_filter output }=\text { Maros_contours minlevel }=0 \text { maxlevel }=10 \text { step }=1
\end{gathered}
$$

where,

input $=$ Name of input raster map.

output $=$ Name for output raster/vector map.

minlevel $=$ Minimum contour level.

maxlevel $=$ Maximum contour level.

step $=$ Interval contour.

To generate a supervised classification map using specifically digitised training areas; we need to create training areas, but before training areas can be digitised, a vector map layer has to be created and added to the layer manager. The process of creating a vector map layer ready for training area digitisation is available from the graphical user interface of GRASS GIS; vector-develop vector map-create a new vector map. The vector training areas then can be converted into raster format using the "v.to.rast" expression (Equation (11)).

The "i.group" expression (Equation (12)) was used to select all relevant bands (blue band of Landsat 7 ETM+, a deep blue coastal band of Landsat 8 OLI, NDVI images, and NDWI images) of the raster images.

To generate statistics from the training area, the "i.gensig" expression (Equation (13)) was used. The input into the "i.gensig" for creation of signature statistics needs a ground truth training area image that is in raster format, which the conversion format has done using Equation (11).

The classification algorithm was employed using the "i.maxlik" expression (Equation (14)) in GRASS GIS. The classification result was converted into vector format using the "r.to.vect" expression (Equation (15)). Quantum GIS software was then used for the final analysis of mangrove forest changes and cartography design. The overall algorithm that was used in this study was shown in Figure 2.

$$
\text { v.to.rast input }=\text { training _ vector output }=\text { training_raster }
$$

i.group group = Landsat7_ group subgroup = Landsat7_subgroup input = B1, NDVI, NDWI

i.gensigtrainingmap $=$ training _ raster group $=$ Landsat7_ group subgroup $=$ Landsat7 $\_$subgroup

$$
\text { signaturefile }=\text { Landsat7_signature }
$$

i.maxlik group $=$ Landsat7 _ group subgroup $=$ Landsat7_ subgroup

$$
\text { signaturefile }=\text { Landsat7 } \_ \text {signature class }=\text { mangrove } \_ \text {class7 }
$$

r.to.vect $-\mathrm{s}$ input $=$ mangrove_class7 output $=$ mangrove_class7 feature $=$ area

where,

input $=$ Name of input vector/raster map.

output $=$ Name for output vector/raster map. 


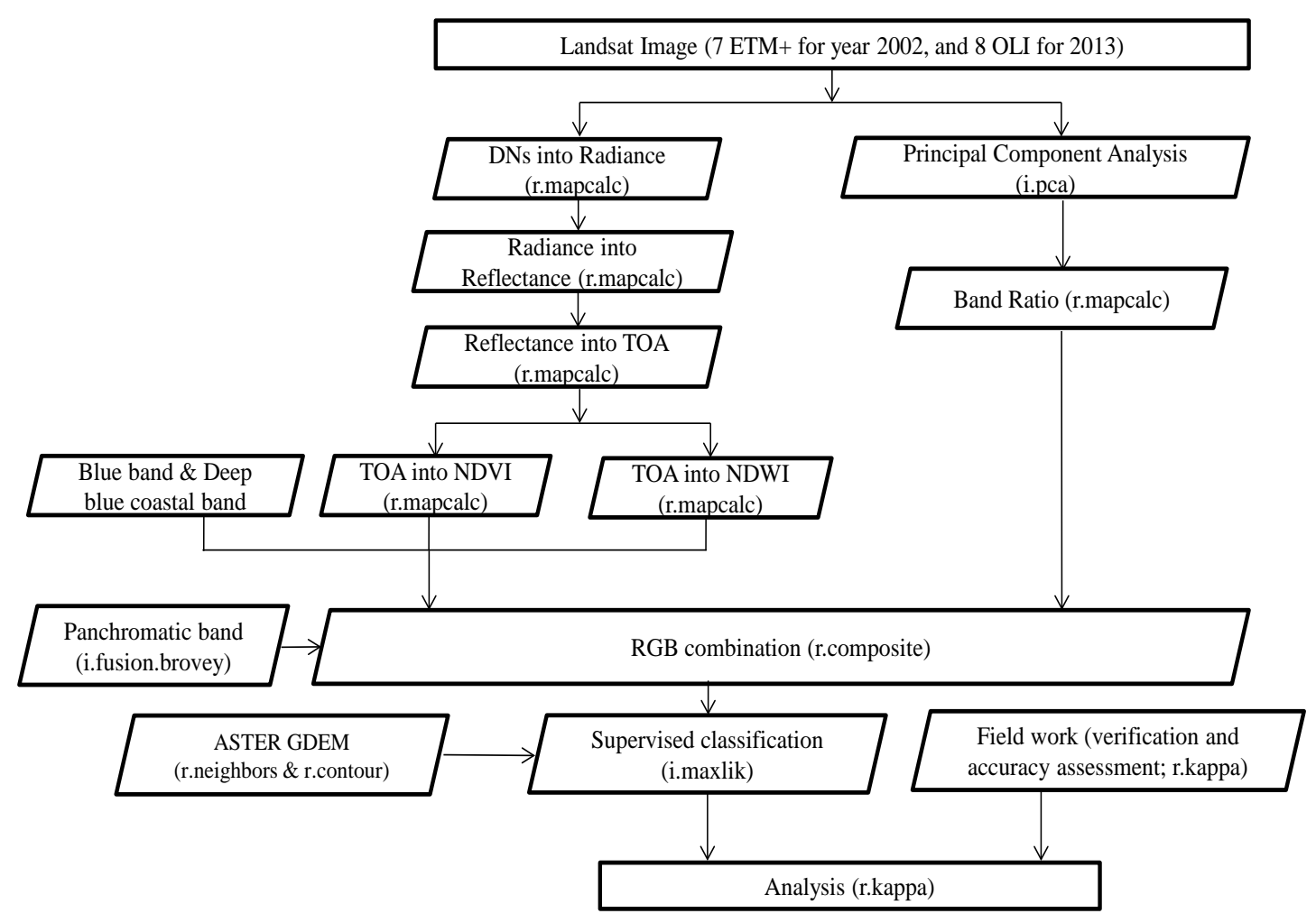

Figure 2. Algorithm performed in this study. Expressions used in GRASS GIS open source software are shown in parentheses. Expressions were input in the command console window of GRASS GIS.

group = Name of imagery group.

subgroup $=$ Name of imagery subgroup.

trainingmap = Name of training area in raster format.

signaturefile $=$ Name of signature file.

class $=$ Name for output classification result.

-s: smoothing the vector data.

feature $=$ Feature type (area).

\subsection{PCA Analysis and Band Ratio}

The classification was based on the band ratio and so the subsequent supervised classification had the possibility of producing the best result if the canopy spectra of mangrove vegetation. In the study of mangroves, Rahman [32] proposed the use of the ratios B4/B2, B5/B7, and B7/B4 of Landsat Enhanced Thematic Mapper Plus $(\mathrm{ETM}+)$ imagery.

However, in the present study, the same band ratio pair cannot be used, since the PCA analysis is dependent to the specific imagery, and that each new image requires a new recalculation. Therefore, we recalculated and combined the band ratio analysis with the principal component analysis (PCA), a common technique for extracting essential features of the data with high dimensionality ([33]-[35]).

PCA is a more powerful approach for feature extraction. PCA identifies the optimum linear combinations of the original channels that can account for the variations of pixel values within an image. Optimum values for coefficients are calculated by a procedure that ensures that the values they produce account for maximum variation within the entire dataset. This set of coefficients provides the maximum information that can be conveyed by any single channel formed by a linear combination of the original channels. If we make an image from all the values formed by applying this procedure to an entire image, we generate a single band of data that provides an optimum depiction of the information. However, the effectiveness of this procedure depends on the calculation of the optimum coefficients. More complete explanation requires the level of detail provided by Davis [36]. 
To perform PCA, this study calculated a variety of variables from all data sets: including eigenvalues, eigenvectors, and percent of importance. These values were calculated for each principal component (PC), and the results were shown in Table 1 and Table 2. To perform PCA in GRASS GIS, we employed "i.pca” expression (Equation (16)).

$$
\text { i.pca input }=\mathrm{B}(\mathrm{i}), \mathrm{B}(\mathrm{ii}), \cdots, \mathrm{B}(\mathrm{n}) \text { output_prefix }=\text { PCA }
$$

where,

input $=$ All band that used in this study.

output_prefix = Name for output raster map.

From the eigenvectors (Table 1 and Table 2), positive and negative loading in PC1 - PC7 was exploited for the appropriate choice of band ratio. In PC1, for example, we obtained Equation (17) for Landsat 7 ETM+, and Equation (18) for Landsat 8 OLI.

$$
\begin{gathered}
\mathrm{PC} 1=-0.45(\mathrm{~B} 1)-0.44(\mathrm{~B} 2)-0.44(\mathrm{~B} 3)-0.35(\mathrm{~B} 4)-0.43(\mathrm{~B} 5)-0.31(\mathrm{~B} 7) \\
\mathrm{PC} 1=-0.20(\mathrm{~B} 1)-0.22(\mathrm{~B} 2)-0.27(\mathrm{~B} 3)-0.29(\mathrm{~B} 4)-0.7(\mathrm{~B} 5)-0.28(\mathrm{~B} 7)
\end{gathered}
$$

where,

B1-5 \& B7 = Digital Numbers for the Landsat 7 ETM+ and Landsat 8 OLI, bands 1 - 5 \& 7.

Since PC1 has the most positive (negative) contribution from B7 (B1), the band ratio derived from PC1 to Landsat $7 \mathrm{ETM}+$ is B1/B7. Similarly, the results for PC2 - PC7 lead to the choice of the ratios B1/B5, B7/B4, $\mathrm{B} 3 / \mathrm{B} 1, \mathrm{~B} 5 / \mathrm{B} 7$, and B3/B2, respectively.

The band ratio derived from PC1 to Landsat 8 OLI is B5/B1. Similarly, the results for PC2 - PC7 lead to the choice of the ratios B5/B2, B5/B7, B7/B4, B7/B2, and B2/B1, respectively.

In accordance with the result of PCA analysis, we then employed GRASS GIS software to make a band ratio image using the "r.mapcalc" expression (Equation (19)).

$$
\text { r.mapcalc BandRatio1 }=\text { B5/B1 }
$$

Table 1. Eigenvectors for Landsat 7 ETM + image.

\begin{tabular}{cccccccc}
\hline & PC1 & PC2 & PC3 & PC4 & PC5 & PC7 \\
\hline Band 1 & -0.455 & -0.596 & 0.405 & 0.458 & 0.053 & -0.244 \\
Band 2 & -0.437 & -0.255 & -0.036 & -0.297 & -0.063 & 0.807 \\
Band 3 & -0.445 & -0.168 & -0.446 & -0.524 & -0.173 & -0.520 \\
Band 4 & -0.346 & 0.488 & 0.647 & -0.376 & 0.258 & -0.123 \\
Band 5 & -0.433 & 0.521 & -0.128 & 0.450 & -0.566 & 0.046 \\
Band 7 & -0.311 & 0.204 & -0.448 & 0.288 & 0.759 & 0.041 \\
\hline
\end{tabular}

Note: The highest positive and negative loading in every PC column is marked as red and yellow shadings, respectively.

Table 2. Eigenvectors for Landsat 8 OLI image.

\begin{tabular}{ccccccc}
\hline & PC1 & PC2 & PC3 & PC4 & PC5 & 0.281 \\
\hline Band 1 & -0.203 & 0.404 & -0.232 & -0.437 & 0.284 \\
Band 2 & -0.221 & 0.422 & -0.255 & -0.304 & -0.729 \\
Band 3 & -0.268 & 0.343 & -0.196 & 0.372 & -0.143 \\
Band 4 & -0.287 & 0.390 & -0.077 & 0.516 & -0.354 \\
Band 5 & -0.703 & -0.596 & -0.349 & -0.112 & -0.116 \\
Band 7 & -0.279 & 0.179 & 0.583 & -0.472 & -0.052 \\
\hline
\end{tabular}

Note: The highest positive and negative loading in every PC column is marked as red and yellow shadings, respectively. 


\subsection{Field Work and Accuracy Assessment}

Extensive field work was carried out September $1^{\text {st }}$, 2013. Location data are collected using Trimble Juno GPS for accuracy assessments. Local photographs and Google Earth imagery were used for visual inspection. Vector points data and fused images were transformed into a KML/KMZ format to enable land cover validation in Google Earth imagery. One hundred points were selected randomly from each classification result, and were then superimposed into Google Earth and a visual assessment was then completed (Figure 3).

To generate a kappa value, we needed to import shapefile data of ground truth into GRASS GIS with "v.in.ogr" expression (Equation (20)), and thereafter convert again the vector to a raster with "v.to.rast" expression (Equation (21)). Then we employed "r.kappa” expression (Equation (22)) in GRASS GIS command console.

$$
\begin{gathered}
\text { v.in.ogrdsn }=\text { /home } / \text { user } / \text { shape _ data layer }=\text { survey_data output }=\text { survey_area } \\
\text { v.to.rast input }=\text { survey_area output }=\text { survey_area } \\
\text { r.kappa classification }=\text { mangrove_class7 reference }=\text { survey_area output }=\text { result_kappa7 }
\end{gathered}
$$

where,

layer $=$ Name for input shapefile vector data.

input $=$ Name for input vector map.

output $=$ Name for output vector/raster map.

classification $=$ Name of raster map containing classification result.

reference $=$ Name of raster map containing reference classes.

output $=$ Name for output file containing error matrix and kappa.

From the field work activity, we found that there are two types of mangrove trees that exist in the study area, Rhizophora and Bruguiera as shown in the following Figure 4.
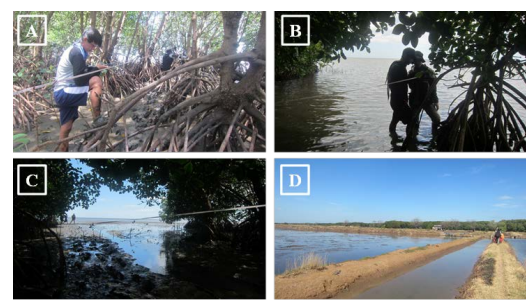

Figure 3. Ground truth and field work activity in the study area; (A), (B), (C) Measuring mangrove area; (D) Fishponds location (milkfish).

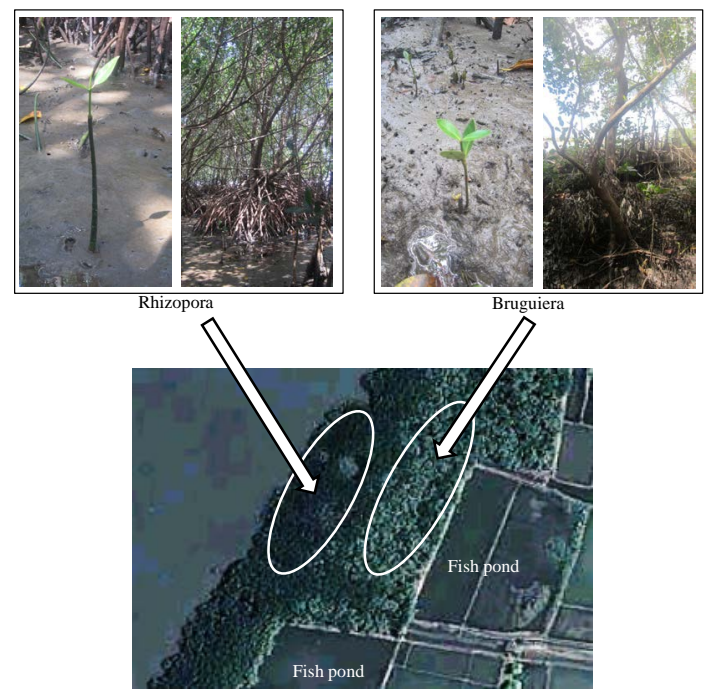

Figure 4. Mangrove types in the study area. Source: very high resolution image of study area is from Google Earth. 
Furthermore, to enhance the analysis, we use the Global Distribution of Mangroves USGS [37] as the reference data. We obtained the mangroves land use map of the study area from http://data.unep-wcmc.org/datasets/21. We then calculate the accuracy assessment to generate a kappa value with the same algorithms (Equation (20) to Equation (21)).

\section{Result and Discussions}

This study utilized ground truth data to evaluate the accuracy of the classified mangrove forest obtained from Landsat 7 ETM+ and Landsat 8 OLI. The field validation and visual assessment through Google Earth imagery was used as reference to check the accuracy of the classified images.

\subsection{RGB Composite Color-Supervised Classification (Maximum Likelihood Decision Rule)}

The maximum likelihood classification decision rule was implemented quantitatively to consider several classes and several spectral channels simultaneously as well as form a powerful classification technique. However, the training area needs to be carefully selected; otherwise the classification result may introduce error. The maximum likelihood classification uses the training area as a means of estimating means and variance of the classes, which are then used to estimate the probabilities. Maximum likelihood classification considers not only the mean, or average, values in assigning classification, but also the variability of the brightness value of each class [38]. Therefore, this study implemented the maximum likelihood classification method and provided substantial confidence in the high level of accuracy of land use in the coastal region.

Table 3 presents the kappa analysis and subsequent accuracy of the classification using RGB composite color. The kappa statistic of 0.95 provided substantial confidence to the methodology utilized.

It can be seen from the RGB composite colors (Figure 5), that the mangrove forests along the coastline are clearly highlighted in light green color. While water bodies (sea water, river, and fish ponds) are represented in blue color.

From the analysis using the Global Distribution of Mangroves as the reference data, the study provided the perfect strength of agreement, with the kappa statistic of 0.98 as the classification image of year 2013 using the RGB composite color-supervised classification (maximum likelihood decision rule).
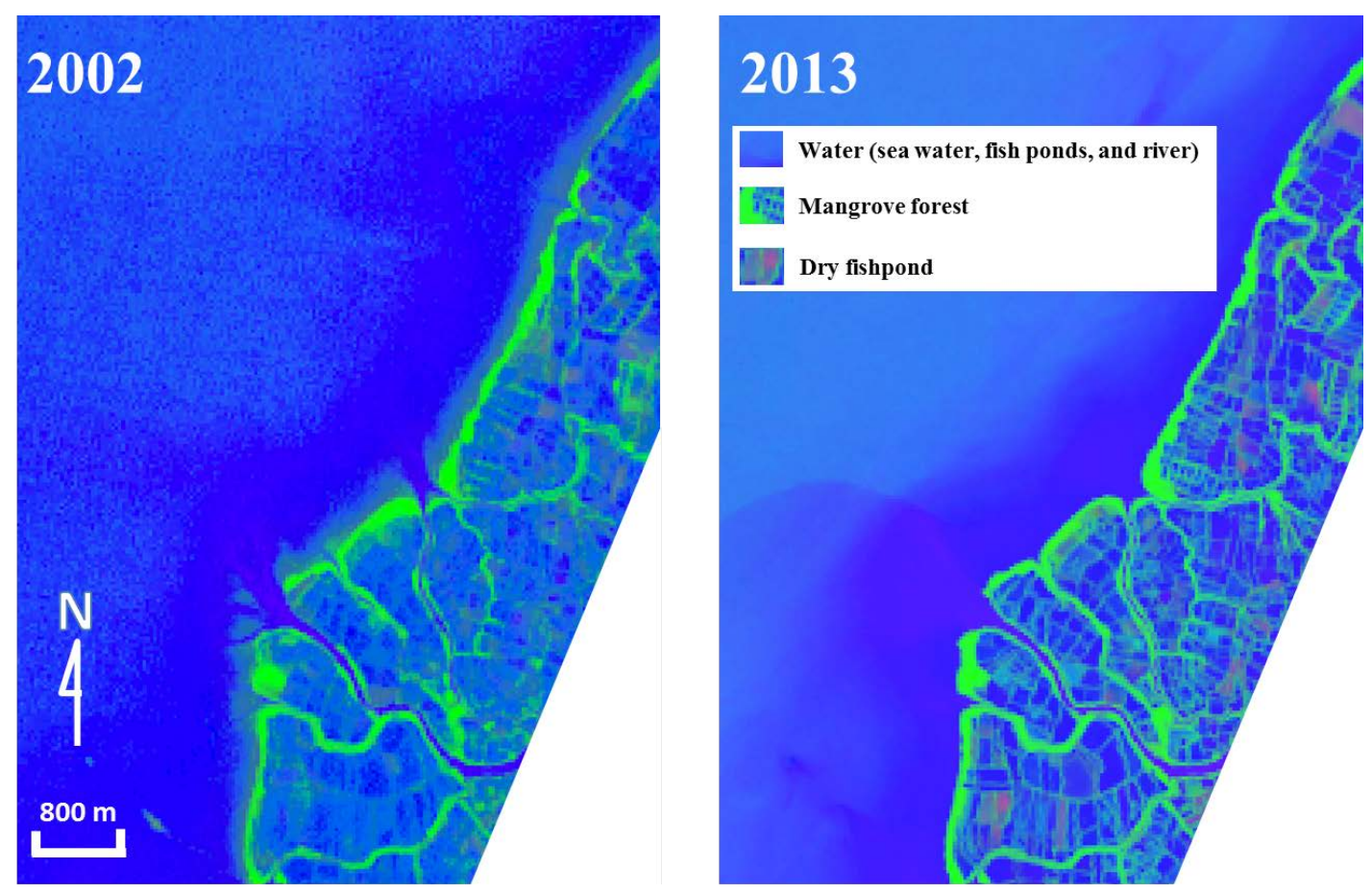

Figure 5. RGB colour composite of the study area for year 2002 and 2013. Deep blue coastal was loaded in the red channel, NDVI images in the green channel, and NDWI images in the blue channel. 
Table 3. Classification accuracy of Landsat 8 OLI using RGB composite color.

\begin{tabular}{ccccc}
\hline Class/Region & Water & Mangrove & Fishpond & Built-up \\
Water & $98.00 \%$ & $0.000 \%$ & $7.000 \%$ & $0.000 \%$ \\
Mangrove & $0.000 \%$ & $98.00 \%$ & $0.000 \%$ & $4.000 \%$ \\
Fishpond & $1.00 \%$ & $0.000 \%$ & $92.00 \%$ & $0.000 \%$ \\
Built-up & $0.000 \%$ & $2.000 \%$ & $0.000 \%$ & 95.00
\end{tabular}

Overall kappa $=\mathbf{0 . 9 5}$

Overall classification accuracy $=\mathbf{9 6 . 4 7} \%$

\subsection{PCA-Band Ratio Classification}

To select the bands for band ratio classification, the eigenvalues and percentage of importance that was produced by PCA method showed that the first three eigenvalues contain approximate $99.10 \%$ and $99.68 \%$ of the total bands of Landsat 7 ETM+ and Landsat 8 OLI respectively. The band ratios of B1/B7, B1/B5, and B7/B4 were found to yield the major features of the classification from Landsat 7 ETM+ images. B5/B1, B5/B2, and B5/B7 yielded the major features of the classification from Landsat 8 OLI images. The kappa analysis of the Landsat 8 OLI classified images using band ratios yielded a value $=0.83$

Furthermore, from the field work activities, mangrove area was observed to decrease due to the expansion of fishpond activity. However, the decrease rate is low (11 ha in period 2002-2013). To promote sustainable development in mangrove forest in the region, community participation in rehabilitation, conservation and management of mangroves had been carried out through mangrove rehabilitation programs supported by the Department of Forestry. Mangrove conservation and rehabilitation were initiated and promoted collaboratively by both local people and governmental institutions [39]. However, it seems that the program was far from success in the Maros Regency.

The results of the supervised classification methods are provided in Figure 6, while the detected changes in mangroves foliage cover are shown in Figure 7.

The spectral characteristics that were obtained from the ETM+ and OLI datasets, based on the physical properties of mangrove forests, in combination with ASTER GDEM data, increased the accuracy of mapping the mangrove forests. In addition, the RGB combination of the NDWI, NDVI, and the band 1 of Landsat 8 OLI, increased the accuracy of the classification. Using this method, mangrove forests have been successfully separated from other coastal land uses, located in the region.

In many cases, human eye interpretation of images was found as one of the best ways of obtaining information. The findings of the present study highlight the importance of integrating types of methods and visual and automated method.

Many studies have been conducted for mangroves forest mapping and assessment, for example Kiruiet [40] mapping mangrove forest in Kenya using Landsat data revealed that Kenya shows high rates of decline in its mangrove forest. However, in this study, aerial photograph data were still used to assess classification accuracy. This method is costly for the region since the aerial photograph data is not available.

Rahman [32] compared the Landsat data for detecting mangrove forests in Sundarbans on both sides of the border between Bangladesh and India. This study employed three different classification methods (i.e. unsupervised classification with $\mathrm{k}$-means clustering, supervised classification using the maximum likelihood decision rule, and band-ratio supervised classification). This study revealed that the band ratio method is better than the unsupervised or supervised classification methods. However, in this study, high cost commercial software was used for imagery processing and analysis.

Furthermore, Santos [41] monitored the mangrove forest conversion in Brazil, and so revealed that shrimp farming is the main anthropogenic activity, occupying the highest area and occurring within the tallest Rhizophora mangle forests. In this study, the SPOT5 data were used to assess classification accuracy. Although, the SPOT5 data is not available in the public domain, it is relatively expensive for mapping and assessment of mangrove forest in the larger region. 


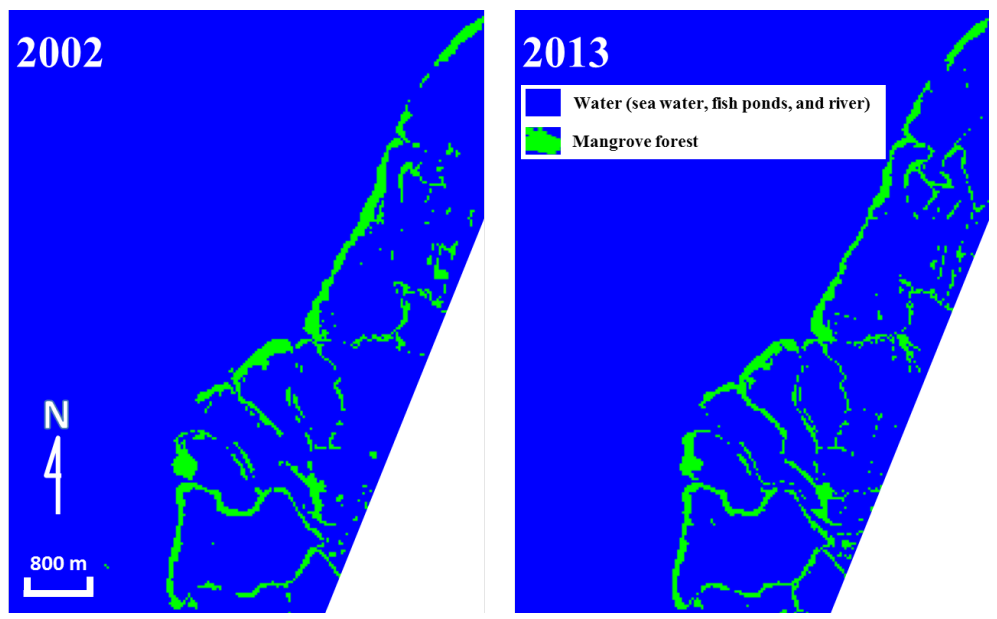

Figure 6. Mangrove forest extraction derived from a supervised classification method. Green color represents mangrove, while blue color represents water bodies (sea water, fishponds, and river).

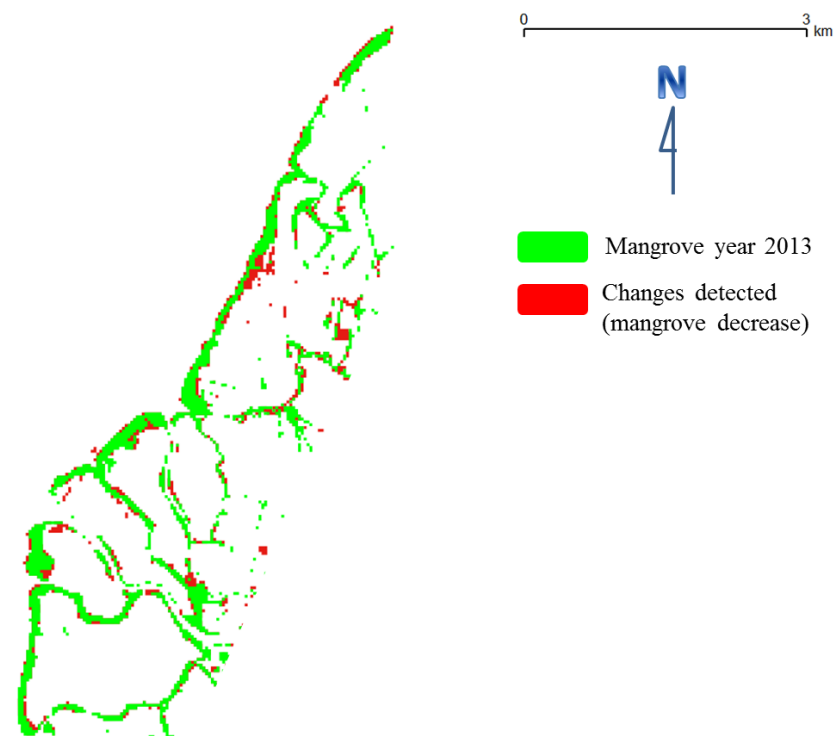

Figure 7. Detected changes in mangrove extents (2002-2013). The green color represents mangrove foliage cover for the year 2013, while red represents the changes detected over the 11 years period.

This study highlights the importance of freely available and less economically geospatial software and data available in the public domain, such as GRASS GIS software and Landsat data, which can be used for such purposes and, consequently, producing information to aid in decision making and elaboration of management plans for coastal conservation.

Freely-available satellite imagery of the entire Earth's surface via the Landsat data and Google Earth allows examination of landscape features in even the most remote areas, including difficult-to-access habitats within them. Here we demonstrated that by linking the open source software with this data available in the public domain. Therefore, it is possible to remotely observe the mangroves forest changes and conversion for less economically developing nations/organization to employ remote sensing methods.

A limitation of this method is the inability to discriminate between different species of mangroves. Furthermore, the frequent existence of clouds in tropical and subtropical areas is considered as the main limitation in using optical remote sensing data, which must be taken into consideration when producing regional maps of mangrove forests. 


\section{Conclusions}

This study has shown that Landsat 7 ETM+ and Landsat 8 OLI are suitable for the regional mapping and assessment of mangrove forests. The algorithm proposed in this study provides an inexpensive framework for the application of mapping and assessing mangroves on a large scale.

The utilisation of the deep blue coastal band in Landsat 8 OLI was useful for highlighting mangroves and separating them from water bodies when combined with the RGB color composite. In the present study, the choice of three bands (deep blue coastal band, NDVI, and NDWI) was suitable, resulting in an accuracy of $96.47 \%$. The band ratios approach resulted in an accuracy of 86.73\%.

GRASS GIS opens source software is freely available for use by universities, government agencies, and other organizations for any GIS applications. The capability of GRASS GIS is comparable with commercial software which has a high cost and is therefore not affordable for developing countries. In this study GRASS GIS has been applied to the coastline environment to monitor and assess the changes of mangrove's foliage.

By linking the open source software with freely-available, the Landsat data and Google Earth satellite imagery, mangroves forest conversion and changes can be observed remotely. By using sequential, the Landsat data and Google Earth images of specific locations over time, this technique could potentially allow rapid, inexpensive remote monitoring of cascading, indirect effects of human activities in mangroves forest nearly anywhere on earth.

Ground truth surveys confirmed that, decreases in the mangrove forest are due to the expansion of fishpond activity. Regular monitoring and assessment is needed in order to monitor the changes in the mangrove environment. Furthermore, understanding the processes of change is also needed in order to minimize the negative impact from the human-environment linkage. This approach has the potential to lead to the sustainable development of the coastal environment.

\section{Acknowledgements}

The author would like to thank the team at Hasanuddin University, Makassar, South Sulawesi, Indonesia for conducting field work to support this study. We would also like to thank the reviewers of this paper and their valuable contribution towards refining the manuscript.

\section{References}

[1] Yanagisawa, H., et al. (2009) The Reduction Effects of Mangrove Forest on a Tsunami Based on Field Surveys at Pakarang Cape, Thailand and Numerical Analysis. Estuarine, Coastal and Shelf Science, 81, 27-37. http://dx.doi.org/10.1016/j.ecss.2008.10.001

[2] Das, S. and Crépin, A.-S. (2013) Mangroves Can Provide Protection against Wind Damage during Storms. Estuarine, Coastal and Shelf Science, 134, 98-107. http://dx.doi.org/10.1016/j.ecss.2013.09.021

[3] Saenger, P., Hegerl, E.J. and Davie, J.D.S. (1983) Global Status of Mangrove Ecosystems by the Working Group on Mangrove Ecosystems of the IUCN Commission on Ecology in Cooperation with the United Nations Environment Programme and the World Wild Life Fund. The Environment, 3, 1-88.

[4] Brander, L.M., Wagtendonk, A.J., Hussain, S.S., McVittie, A., Verburg, P.H., deGroot, R.S. and van der Ploeg, S. (2013) Ecosystem Service Values for Mangroves in Southeast Asia: A Meta-Analysis and Value Transfer Application. Ecosystem Service, 1, 62-69.

[5] Forestry Paper FAO 153 (2007) The World's Mangroves 1980-2005. Food and Agriculture Organization of the United Nations, Rome. ftp://ftp.fao.org/docrep/fao/010/a1427e/a1427e00.pdf

[6] Burbridge, P.R. (1982) Management of Mangrove Exploitation in Indonesia. Applied Geography, 2, 39-54. http://dx.doi.org/10.1016/0143-6228(82)90016-9

[7] Choong, E.T., Wirakusumah, R.S. and Achmadi, S.S. (1990) Mangrove Forest Resources in Indonesia. Forest Ecology and Management, 33/34, 45-57. http://dx.doi.org/10.1016/0378-1127(90)90183-C

[8] Dutrieux, E. (1991) Study of the Ecological Functioning of the Mahakam Delta (East Kalimantan, Indonesia). Estuary, Coastal and Shelf Science, 32, 415-420. http://dx.doi.org/10.1016/0272-7714(91)90053-E

[9] Verheugt, W.J.M., Purwoko, A., Danielsen, F., Skov, H. and Kadarisman, R. (1991) Integrating Mangrove and Swamp Forests Conservation with Coastal Lowland Development; the BanyuasinSembilang Swamps Case Study, South Sumatra Province, Indonesia. Landscape and Urban Planning, 20, 85-94.

http://dx.doi.org/10.1016/0169-2046(91)90096-5 
[10] Ruitenbeek, H.J. (1994) Modelling Economy-Ecology Linkages in Mangroves: Economic Evidence for Promoting Conservation in Bintuni Bay, Indonesia. Ecological Economics, 10, 233-247. http://dx.doi.org/10.1016/0921-8009(94)90111-2

[11] Babo, N.R. and Froehlich, J.W. (1998) Community-Based Mangrove Rehabilitation: A Lesson Learned from East Sinjai, South Sulawesi, Indonesia. The World Bank, Washington DC.

[12] Armitage, D. (2004) Socio-Institutional Dynamics and the Political Ecology of Mangrove Forest Conservation in Central Sulawesi, Indonesia. Continental Shelf Research, 24, 2535-2551.

[13] Sidik, A.S. (2008) The Changes of Mangrove Ecosystem in Mahakam Delta, Indonesia: A Complex Social Environmental Pattern of Linkages in Resources Utilization. Proceedings of the South China Sea Conference 2008 on the South China Sea: Sustaining Ocean Productivities, Maritime Communities and the Climate, Kuantan, 25-29 November 2008, 27-46.

[14] Duke, N.C., Meynecke, J.O., Dittmann, S., Ellison, A.M., Anger, K., Berger, U., Cannicci, S., Diele, K., Ewel, K.C., Field, C.D., Koedam, N., Lee, S.Y., Marchand, C., Nordhaus, I. and Dahdouh-Guebas, F. (2007) A World without Mangroves? Science, 317, 41b-42b. http://dx.doi.org/10.1126/science.317.5834.41b

[15] Alongi, D.M. (2002) Present State and Future of the World's Mangrove Forests. Environmental Conservation, 29, 331349. http://dx.doi.org/10.1017/S0376892902000231

[16] Giri, C., Zhu, Z., Tieszen, L.L., Singh, A., Gillette, S. and Kelmelis, J.A. (2008) Mangrove Forest Distributions and Dynamics (1975-2005) of the Tsunami-Affected Region of Asia. Journal of Biogeography, 35, 519-528.

[17] Yuwono, E., Jennerjahn, T.C., Nordhaus, I., Ardli, E.R., Sastranegara, M.H. and Pribadi, R. (2007) Ecological Status of Segara Anakan, Indonesia: A Mangrove-Fringed Lagoon Affected by Human Activities. Asian Journal of Water, Environment and Pollution, 4, 61-70.

[18] Dahuri, R., et al. (2001) Pengelolaan Sumber Daya Wilayah Pesisirdan Lautan Secara Terpadu. Pradnya Paramita, Bogor.

[19] Ardli, E.R. (2007) Spatial and Temporal Dynamics of Mangrove Conversion at the Segara Anakan Cilacap, Java, Indonesia. In: Yuwono, E., Jennerjahn, T., Sastanegara, M.H. and Sukardi, P., Eds., Synopsis of Ecological and SocioEconomic Aspects of Tropicalcoastal Ecosystem with Special Reference to Segara Anakan, Research Institute, University of Jenderal Soedirman, Purwokerto, 11-20.

[20] Gilman, E., Ellison, J., Duke, N.C. and Field, C. (2008) Threats to Mangroves from Climate Change and Adaptation Options: A Review. Aquatic Botany, 89, 237-250. http://dx.doi.org/10.1016/j.aquabot.2007.12.009

[21] Soegiarto, A. (1984) The Mangrove Ecosystem in Indonesia, Its Problems and Management. In: Teas, H.J., Ed., Physiology and Management of Mangroves, Dr W. Junk Publishers, The Hague, 69-78.

[22] Souza-Filho, P.W.M., Martins, E.S.F. and Costa, F.R. (2006) Using Mangroves as a Geological Indicator of Coastal Changes in the Bragança Macrotidal Flat, Brazilian Amazon: A Remote Sensing Data Approach. Ocean \& Coastal Management, 49, 462-475. http://dx.doi.org/10.1016/j.ocecoaman.2006.04.005

[23] Li, M.S., Mao, L.J., Shen, W.J., Liu, S.Q. and Wei, A.S. (2013) Change and Fragmentation Trends of Zhanjiang Mangrove Forests in Southern China Using Multi-Temporal Landsat Imagery (1977-2010). Estuarine, Coastal and Shelf Science, 130, 111-120. http://dx.doi.org/10.1016/j.ecss.2013.03.023

[24] Nascimento, W.R., Souza-Filho, P.W.M., Proisy, C., Lucas, R.M. and Rosenqvist, A. (2013) Mapping Changes in the Largest Continuous Amazonian Mangrove Belt Using Object-Based Classification of Multisensor Satellite Imagery. Estuarine, Coastal and Shelf Science, 117, 83-93. http://dx.doi.org/10.1016/j.ecss.2012.10.005

[25] NASA (2013) Landsat 8 Instruments. http://www.nasa.gov/mission_pages/landsat/spacecraft/index.html\#.UdEl3fn0F8E

[26] NASA (1998) Landsat 7 Science Data Users Handbook. http://landsathandbook.gsfc.nasa.gov/pdfs/Landsat7_Handbook.pdf

[27] USGS (2013) Using the USGS Landsat 8 Product. https://landsat.usgs.gov/Landsat8 Using Product.php

[28] Shapiro, M. and Westervelt, J. (1992) R.MAPCALC: An Algebra for GIS and Image Processing. Technical Report, US-Army CERL, Champaign.

[29] Rouse, J.W., Haas, R.H., Schell, J.A., Deering, D.W. and Harlan, J.C. (1974) Monitoring the Venal Advancement and Retrogradation (Green Wave Effect) of Natural Vegetation. NASA/GSCF Final Report, Greenbelt.

[30] Gao, B.C. (1996) NDWI-A Normalized Difference Vegetation Index for Remote Sensing of Vegetation Liquid Water from Space. Remote Sensing of Environment, 58, 257-266. http://dx.doi.org/10.1016/S0034-4257(96)00067-3

[31] Pohl, C. and van Genderen, J.L. (1998) Multisensor Image Fusion in Remote Sensing: Concepts, Methods and Application. International Journal of Remote Sensing, 19, 823-854. http://dx.doi.org/10.1080/014311698215748 
[32] Rahman, M., Ullah, R., Lan, M., Sri Sumantyo, J.T., Kuze, H. and Tateishi, R. (2013) Comparison of Landsat Image Classification Methods for Detecting Mangrove Forests in Sundarbans. International Journal of Remote Sensing, 34, 1041-1056.

[33] Singh, A. and Harrison, A. (1985) Standardized Principal Components. International Journal of Remote Sensing, 6, 883-896.

[34] Lillesand, T.M. and Kiefer, R.W. (2000) Remote Sensing and Image Interpretation. John Wiley and Sons, New York.

[35] Rogerson, P.A. (2002) Change Detection Thresholds for Remotely Sensed Images. Journal of Geographical Systems, 4, 85-97.

[36] Davis, J.C. (2002) Statistics and Data Analysis in Geology. Wiley, New York, 638.

[37] Giri, C., Ochieng, E., Tieszen, L.L., Zhu, Z., Singh, A., Loveland, T., Masek, J. and Duke, N. (2011) Global Distribution of Mangroves Forests of the World Using Earth Observation Satellite Data. In Supplement to: Giri, et al. 2011, UNEP World Conservation Monitoring Centre, Cambridge. http://data.unep-wcmc.org/datasets/21

[38] Campbell, J.B. and Wynne, R.H. (2011) Introduction to Remote Sensing. 5th Edition Guilford, New York, 667 p.

[39] Amri, A. (2005) Community Participation in Rehabilitation, Conservation and Management of Mangroves: Lessons from Coastal Areas of South Sulawesi, Indonesia. African Study Monographs, 29, 19-30. http://jambo.africa.kyoto-u.ac.jp/kiroku/asm suppl/abstracts/pdf/ASM s29/1-Andi\%20final.pdf

[40] Kirui, K.B., Kairo, J.G., Bosire, J., Viergever, K.M., Rudra, S., Huxham, M. and Briers, R.A. (2013) Mapping of Mangrove Forest Land Cover Change along the Kenya Coastline Using Landsat Imagery. Ocean \& Coastal Management, 83, 19-24. http://dx.doi.org/10.1016/j.ocecoaman.2011.12.004

[41] Santos, L.C.M., Matos, H.R., Schaeffer-Novelli, Y., Cunha-Lignon, M., Bitencourt, M.D., Koedam, N. and DahdouhGuebas, F. (2014) Anthropogenic Activities on Mangrove Areas (São Francisco River Estuary, Brazil Northeast): A GIS-Based Analysis of CBERS and SPOT Images to Aid in Local Management. Ocean \& Coastal Management, 89, 39-50. http://dx.doi.org/10.1016/j.ocecoaman.2013.12.010 
Scientific Research Publishing (SCIRP) is one of the largest Open Access journal publishers. It is currently publishing more than 200 open access, online, peer-reviewed journals covering a wide range of academic disciplines. SCIRP serves the worldwide academic communities and contributes to the progress and application of science with its publication.

Other selected journals from SCIRP are listed as below. Submit your manuscript to us via either submit@scirp.org or Online Submission Portal.
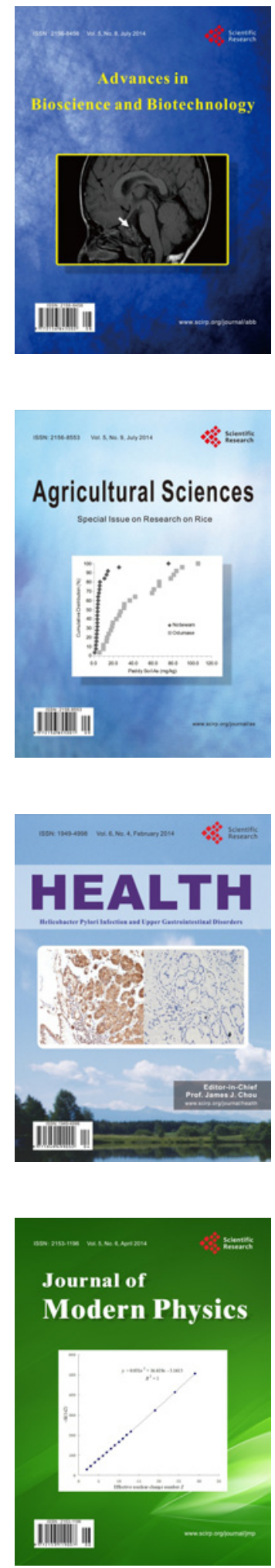
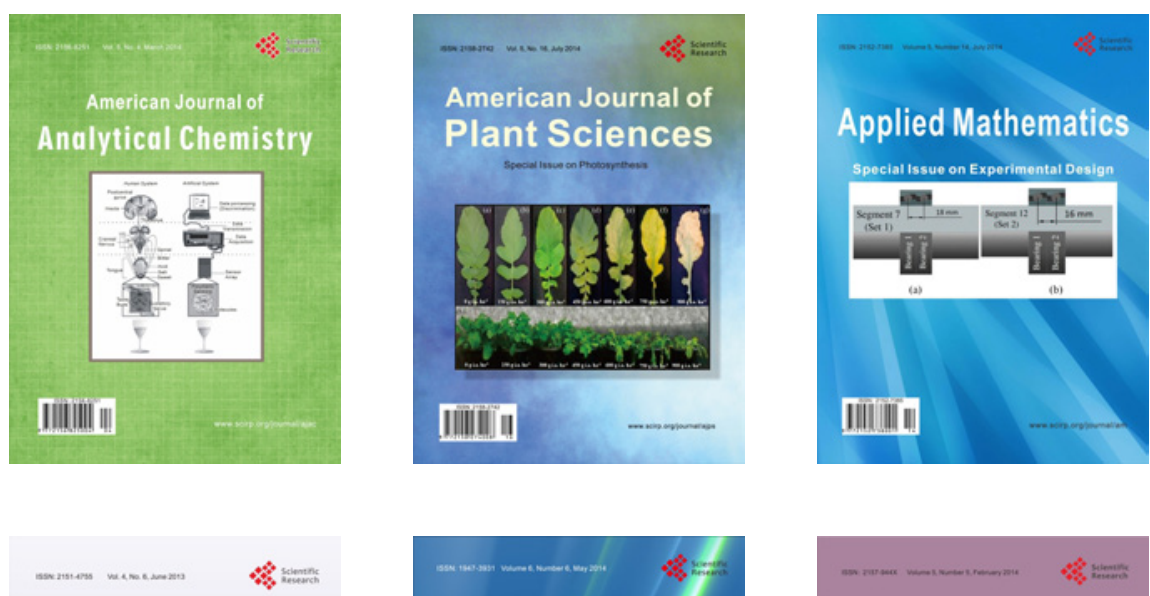

Creative Education
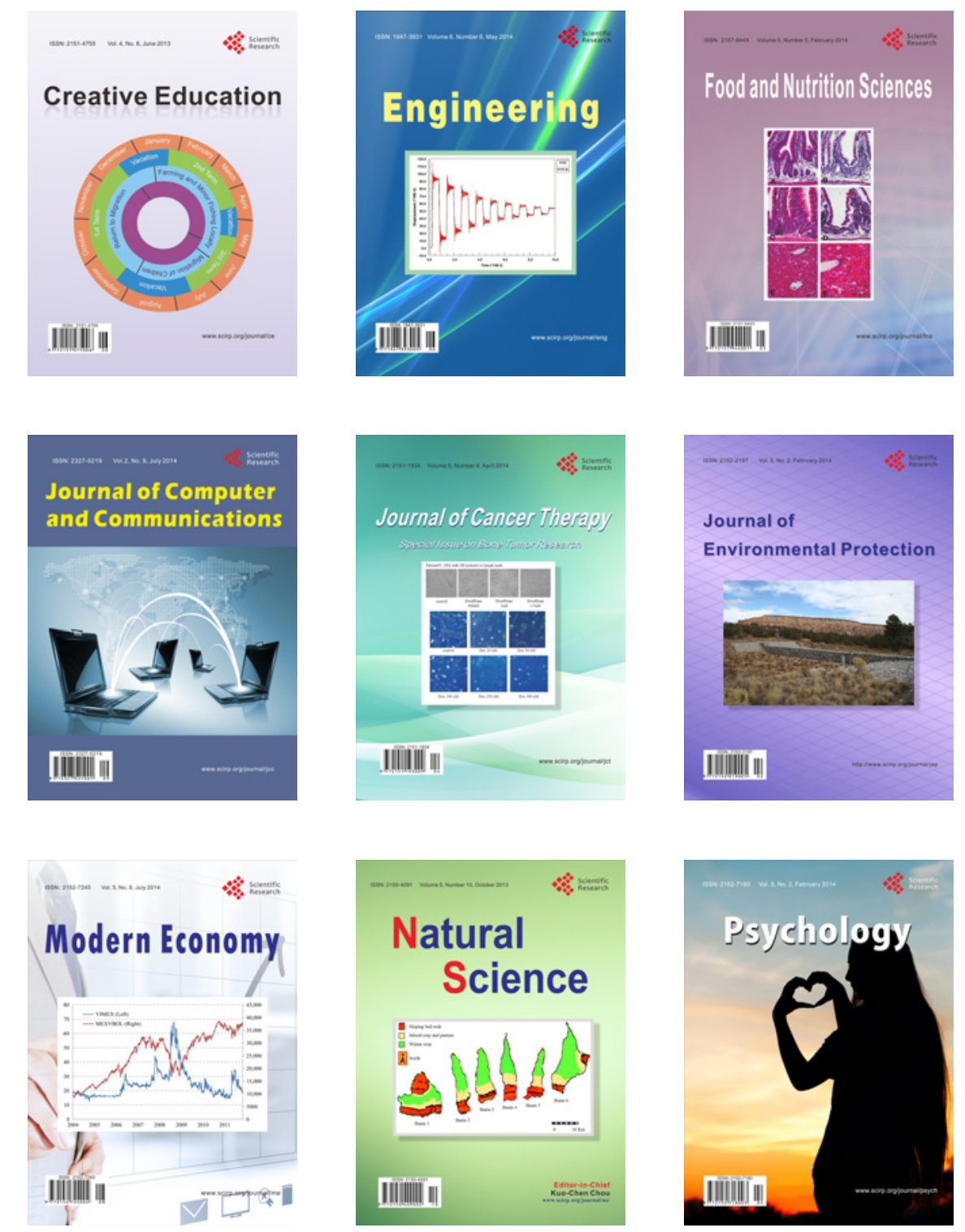